\title{
Insertion element IS1296 in Mycoplasma mycoides subsp. mycoides small colony identifies a European clonal line distinct from African and Australian strains
}

\author{
Xiaoxing Cheng, ${ }^{1}$ Jacques Nicolet, ${ }^{1}$ François Poumarat, ${ }^{2}$ José Regalla, ${ }^{3}$ \\ François Thiaucourt ${ }^{4}$ and Joachim Frey ${ }^{1}$
}

Author for correspondence: Joachim Frey. Tel: +4131631 2484. Fax: +41316312634. e-mail: JFREY@VBI.UNIBE.CH

1 Institute for Veterinary Bacteriology, University of Berne, Laenggasstrasse 122, CH-3012 Berne, Switzerland

2 CNEVA, Laboratoire de Pathologie Bovine, 31 av. Tony-Garnier, PB 7033, F-69342 Lyon, France

3 Laboratório Nacional de Veterinária, Estrada de Benfica 701, P-1500 Lisboa, Portugal

4 CIRAD-EMVT, 10 rue Pierre-Curie, F-94704 Maisons-Alfort, France
Strains of Mycoplasma mycoides subsp. mycoides small colony (SC) type, the agent of contagious bovine pleuropneumonia (CBPP), were analysed with respect to the polymorphism of distribution of a newly discovered insertion element, IS1296, on the chromosome. Analysis of 64 strains isolated from Europe, Africa and Australia, including four vaccine strains and the type strain PG1, revealed ten different IS patterns, forming two main clusters. The European strains originated from outbreaks of CBPP in different countries, and from various other sources such as semen and preputial washings from cattle, lungs from goats and buffalo, and milk from sheep. They showed identical IS1296 patterns, except one strain which had an additional IS1296 element, but the pattern belonged to the same cluster. This shows that the strains from Europe form a clonal lineage. The strains originating from different geographical parts of the African continent and from Australia showed four closely related IS1296 patterns which belong to a separate cluster. This indicates that strains from Africa and Australia form a clonal lineage different from that of the European strains, suggesting that the sporadic cases of CBPP that have re-emerged in Europe almost 15 years after the last declared endemic case in 1967 arose from an established reservoir within Europe rather than being the result of repeated importation from Africa and Australia. While most strains from Africa and Australia had the same IS1296 pattern, all vaccine strains could be distinguished by an individual pattern. The type strain PG1 also had a particular IS1296 pattern which belongs to the cluster of the strains from Africa and Australia. The molecular definition of clonality of $M$. mycoides subsp. mycoides SC strains with IS1296 represents a rapid and reproducible method for subtyping and differentiation of vaccine strains. It permits at the present time the definition of two main clonal lines, one including the strains from the European continent and a second with strains from Africa and Australia.

Keywords: Mycoplasma mycoides subsp. mycoides SC, insertion element IS1296, contagious bovine pleuropneumonia

\section{INTRODUCTION}

Mycoplasma mycoides subsp. mycoides biotype small colony (SC) belongs to the so-called 'mycoides cluster', a group

Abbreviations: CBPP, contagious bovine pleuropneumonia; FAO, Food and Agriculture Organization; SC, small colony. of closely related infectious mycoplasmas including $M$. mycoides subsp. mycoides biotype large colony (LC), M. mycoides subsp. capri, Mycoplasma capricolum subsp. capricolum, M. capricolum subsp. capripneumoniae and Mycoplasma sp. 'bovine group 7' (Cottew et al., 1987; Abu Groun et al., 1994; Taylor et al., 1992). M. mycoides subsp. mycoides SC is the infectious agent of contagious bovine 
pleuropneumonia (CBPP), a severe contagious disease in cattle and buffalo (ter Laak, 1992). Due to its high socioeconomic impact in endemic regions, CBPP is declared by the Office International des Epizooties as a serious disease belonging to list $\mathrm{A}$, requiring special international measures. The disease was endemic on all continents during the 19th century and the beginning of the 20th century, but was subsequently eradicated from Europe, the United States, South Africa and Australia by strict application of sanitary measures. The last case of CBPP in Europe was reported in 1967 from Spain. Since 1980, however, outbreaks have been reported from France, Portugal, Spain and Italy (ter Laak, 1992). At the present time the disease is still endemic in Africa and Asia. Due to increasing international trade, the spread of CBPP presents a renewed danger and demands the development and implementation of modern and efficient control programmes. There is therefore a requirement for specific diagnostic tests and methods for strain identification to establish the sources and reservoirs of infections.

Despite the fact that $M$. mycoides subsp. mycoides SC was the first mycoplasma to be isolated (Nocard \& Roux, 1898), and that it is an important contagious pathogen, little is known about this organism. So far, the size and a physical map of the chromosome of the type strain PG1 has been established (Pyle et al., 1990), and methods for species identification and detection have been developed based on PCR amplification of DNA segments of unknown function (Bashiruddin et al., 1994a, b; Dedieu et al., 1994), or on monoclonal antibodies (Brocchi et al., 1993). Antigenic variability has been reported for $M$. mycoides subsp. mycoides SC (Poumarat \& Solsona, 1994; Costas et al., 1987), but the variable antigens are not yet well-defined and are difficult to apply for strain identification. Hence no practical epidemiological markers have yet been established for studies of field isolates.

Bacterial insertion sequences are transposable genetic elements of about 800-2500 bp (Galas \& Chandler, 1989). Several such elements have been used as molecular DNA fingerprinting markers for identification and subtyping of pathogenic bacterial strains in epidemiological studies. The method has been proved particularly useful for Mycobacterium tuberculosis (van Embden et al., 1993; Small et al., 1994) and for Salmonella (Stanley et al., 1993). The insertion sequence IS1296, recently identified in subsp. mycoides SC is present in 19 copies in the type strain PG1 (Frey et al., 1995). IS1296 was also detected in low copy numbers in subsp. mycoides LC and in Mycoplasma sp. 'bovine group 7' (Frey et al., 1995). In the present study we have employed IS1296 fingerprinting to analyse 64 strains from different countries and continents, including four vaccine strains and type strain PG1. We show the usefulness of IS1296 as a molecular marker for strain identification and subtyping and for the identification of clonal lineages and their short-term evolutionary relationships within $M$. mycoides subsp. mycoides SC.

\section{METHODS}

Strains, growth conditions and DNA extraction. Strains of $M$. mycoides subsp. mycoides SC used in this study and their country of origin are listed in Table 1 . Cultures of $M$. mycoides subsp. mycoides SC were made in a standard mycoplasma medium (Bannerman \& Nicolet, 1971) to a density of $10^{8}-10^{9}$ cells $\mathrm{ml}^{-1}$, harvested by centrifugation, washed in TE buffer $(10 \mathrm{mM}$ Tris, $1 \mathrm{mM}$ EDTA, pH 7) and resuspended in 0.1 vols TE buffer. A volume of $100 \mu \mathrm{l}$ of resuspended cells was then lysed by addition of $500 \mu \mathrm{l}$ GES buffer ( $5 \mathrm{M}$ guanidium thiocyanate, $100 \mathrm{mM}$ EDTA, $0.5 \%$ sarkosyl) for $10 \mathrm{~min}$ at room temperature, cooled on ice and then mixed with $250 \mu \mathrm{l} 7.5 \mathrm{M}$ ammonium acetate, $\mathrm{pH} 7 \cdot 7$. The lysate was then extracted three times with $500 \mu \mathrm{l}$ (phenol:chloroform: isoamylalcohol, $49 \cdot 5: 49 \cdot 5: 1$ ) (Fluka) and the DNA was then precipitated by the addition of 0.7 vols 2-propanol and centrifugation at 12000 r.p.m. for $15 \mathrm{~min}$ at $4^{\circ} \mathrm{C}$ in an Eppendorf centrifuge. The pellet was washed three times with $80 \%$ ethanol, dried, and resuspended in $100 \mu \mathrm{l}$ TE buffer. DNA concentration was determined spectrophotometrically with a GeneQuantII (Pharmacia Biotech).

Non-radioactive labelling of a specific IS1296 probe and Southern blot analysis. For analysis of large numbers of $M$. mycoides subsp. mycoides SC strains by IS1296 fingerprinting with non-radioactive hybridization, a specific probe was labelled by digoxigenin-11-dUTP (Boehringer Mannheim) in a PCR reaction. Plasmid pJFFsc1 155 was used as template. It contains an internal 828 bp EcoRI fragment of IS1296 (nt 528 to nt 1355) (Frey et al., 1995) cloned into the EcoRI site of vector pBluescriptII SK $(-)$ (Stratagene). The primer oligonucleotides used, T3S (5'-AAT'TAACCC'TCACTAAAGGG-3') and T7S (5'-GTAATACGACTCACTATAGGGC-3'), match the $\mathrm{T}_{3}$ and $\mathrm{T}_{7}$ promoter sequences of pBluescriptII $\mathrm{SK}(-)$. The labelling reaction was done in a DNA thermal cycler (Gene Amp 9600; Perkin Elmer Cetus). Purified plasmid pJFFsc1a5 $(100 \mathrm{pg})$ was added to $50 \mu \mathrm{l}$ TAQ-PCR $\operatorname{mix}(10 \mathrm{mM}$ Tris $/ \mathrm{HCl}$, $\mathrm{pH} \mathrm{8.3,1.5} \mathrm{mM} \mathrm{MgCl} 2,50 \mathrm{mM} \mathrm{KCl}, 0.005 \%$ Tween 20, 0.005\% NP 40 detergent, $170 \mu \mathrm{M}$ of each dNTP, $50 \mu \mathrm{M}$ digoxigenin-11dUTP, $0.25 \mathrm{mM}$ T3S and T7S oligonucleotides). Per reaction, 0.5 units Taq DNA polymerase (Boehringer Mannheim) were added, and the samples were subjected to 35 cycles of amplification consisting of $30 \mathrm{~s}$ at $94^{\circ} \mathrm{C}, 30 \mathrm{~s}$ at $56^{\circ} \mathrm{C}, 1 \mathrm{~min}$ at $72{ }^{\circ} \mathrm{C}$.

Genomic mycoplasmal DNA was digested with the corresponding restriction enzyme, separated electrophoretically on a $0.7 \%$ agarose gel, transferred onto positive charged nylon membrane (Boehringer Mannheim), and denatured as described by standard protocols (Ausubel et al., 1990). The membrane was pre-incubated with $20 \mathrm{ml}$ hybridization buffer [ $5 \times \operatorname{SSC}(1 \times$ $\mathrm{SSC}$ is $150 \mathrm{mM} \mathrm{NaCl}, 15 \mathrm{mM}$ sodium citrate, $\mathrm{pH} 7 \cdot 7)], 0 \cdot 1 \%$ $N$-lauroylsarcosine, $0.02 \% \mathrm{SDS}$, and $1 \%(\mathrm{w} / \mathrm{v})$ blocking reagent (Boehringer Mannheim) per $100 \mathrm{~cm}^{2}$ membrane at $68{ }^{\circ} \mathrm{C}$ for $2 \mathrm{~h}$, and then hybridized with $2.5 \mathrm{ml}$ hybridization buffer containing $1 \mu \mathrm{g}$ digoxigenin-11-dUTP labelled IS1296 probe per $100 \mathrm{~cm}^{2}$ membrane for $18 \mathrm{~h}$ at $68^{\circ} \mathrm{C}$. The membrane was washed twice for $5 \mathrm{~min}$ at room temperature with $2 \times$ SSC containing $0.1 \% \mathrm{SDS}$, and twice for $15 \mathrm{~min}$ at $68^{\circ} \mathrm{C}$ with $0.2 \times$ SSC containing $0 \cdot 1 \%$ SDS. The digoxigenin-labelled probe was detected using phosphatase-labelled anti-digoxigenin antibodies (Boehringer Mannheim) according to the producer's instructions.

\section{RESULTS}

\section{Standard method for fingerprinting}

Southern blot hybridization of IS1296 probe with HindIII-digested DNA from type strain PG1, the African field strain Afadé, and a European field strain L2 (isolated 

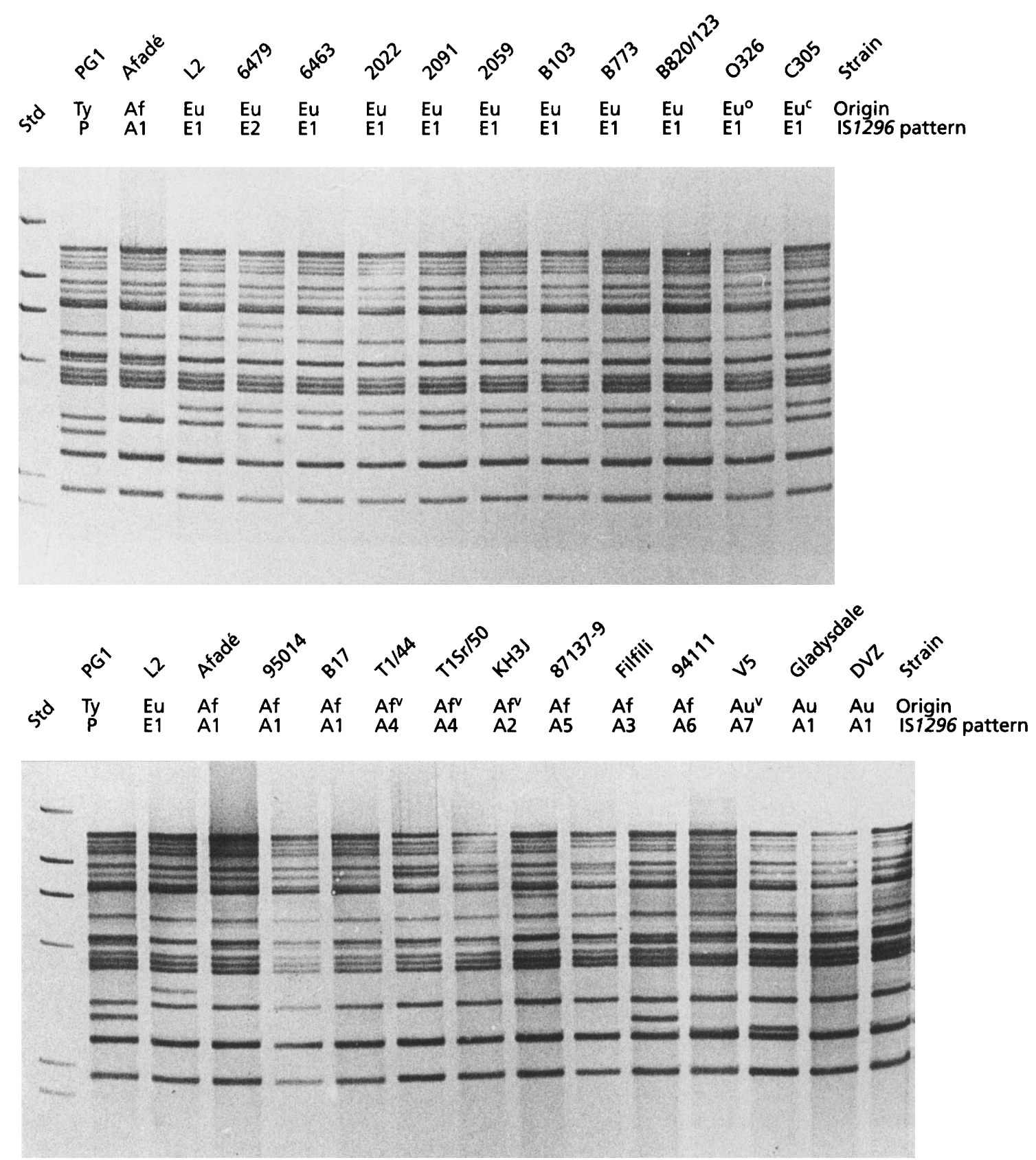

Fig. 1. Southern blot hybridization of Hindlll-digested DNA of a selection of $M$. mycoides subsp. mycoides SC strains hybridized to a IS1296 probe. The strains are described in Table 1. Eu, Europe; Af, Africa; Au, Australia, Ty, type strain. Superscripts: $v$, vaccine strain; $c$, caprine strain; o, ovine strain. All other strains shown are from bovine lungs. Upper blot shows strains from Europe in comparison to PG1 and Afadé. Lower blot shows strains from Africa and Australia in comparison to PG1 and L2. Std, molecular mass standards: $23 \cdot 1,9 \cdot 4,6 \cdot 6,4 \cdot 4,2 \cdot 3$ and $2 \cdot 0 \mathrm{kbp}$.

by our laboratory from pathological lung material from Italy) showed distinct hybridization patterns for each strain (Fig. 1). Type strain PG1 showed 19 bands, while strains Afadé and L2 showed 18 bands. Comparative analysis of the bands from these strains for their positions relative to the molecular mass standards revealed one difference between PG1 (pattern P) and Afadé (pattern A1), three differences between PG1 and L2 (pattern E1), and two differences between Afadé and L2. The same results, but different banding patterns, were obtained when the mycoplasmal DNA was digested with $B g l \mathrm{II}$ or with SpeI instead of HindIII. This indicates that the different banding patterns reflect chromosomal arrangements probably induced by transposition events. Several other restriction enzymes could not be used to create restriction fragment length polymorphisms because they produced bands of high molecular mass, or cut within IS1296 (Frey et al., 1995). Since HindIII-digested DNA 
Table 1. Strains of $M$. mycoides subsp. mycoides $\mathrm{SC}$ used

\begin{tabular}{|c|c|c|c|c|c|}
\hline Strain & Collection* & Origin & Isolated & Host & IS1296 \\
\hline PG1 (NCTC 10114) & NCTC & Unknown & 1931 & Cattle & $\mathbf{P}$ \\
\hline PG1 (LPB 241) & LPB & Unknown & 1931 & Cattle & $\mathrm{P}$ \\
\hline 2059 & LPB & Spain & 1984 & Cattle/lung & E1 \\
\hline 6363 & LPB & Spain & 1991 & Cattle/lung & E1 \\
\hline 6364 & LPB & Spain & 1991 & Cattle/lung & E1 \\
\hline B103 & LNV & Portugal & 1986 & Cattle/lung & E1 \\
\hline B $773 / 125$ & LNV & Portugal & 1991 & Cattle/semen & E1 \\
\hline $\mathrm{B} 820 / 123$ & LNV & Portugal & 1991 & Cattle/preputial wash & E1 \\
\hline B820/124 & LNV & Portugal & 1991 & Cattle/preputial wash & E1 \\
\hline $\mathrm{C} 305$ & LNV & Portugal & 1993 & Goat/lung & E1 \\
\hline $\mathrm{C} 425$ & LNV & Portugal & 1993 & Goat/lung & E1 \\
\hline O326 & LNV & Portugal & 1993 & Sheep/milk & E1 \\
\hline O512 & LNV & Portugal & 1993 & Sheep/milk & E1 \\
\hline O526 & LNV & Portugal & 1993 & Sheep/milk & E1 \\
\hline PO 2 & CIRAD & France & 1980 & Cattle/lung & E1 \\
\hline 2022 & LPB & France & 1984 & Cattle/lung & E1 \\
\hline 2091 & LPB & France & 1984 & Cattle/lung & E1 \\
\hline 2117 & LPB & France & 1984 & Cattle/lung & E1 \\
\hline L2 & IVBBE & Italy & 1993 & Cattle/lung & E1 \\
\hline 402 & LPB & Italy & 1990 & Cattle/lung & E1 \\
\hline 4813 & LPB & Italy & 1990 & Cattle/lung & E1 \\
\hline 6456 & LPB & Italy & 1992 & Cattle/lung & E1 \\
\hline 6461 & LPB & Italy & 1992 & Cattle/lung & E1 \\
\hline 6463 & LPB & Italy & 1992 & Cattle/lung & E1 \\
\hline 6465 & LPB & Italy & 1992 & Cattle/lung & $\mathrm{E} 1$ \\
\hline 6466 & LPB & Italy & 1992 & Cattle/lung & E1 \\
\hline 6467 & LPB & Italy & 1992 & Cattle/lung & E1 \\
\hline 6468 & LPB & Italy & 1992 & Cattle/lung & E1 \\
\hline 6470 & LPB & Italy & 1992 & Cattle/lung & E1 \\
\hline 6471 & LPB & Italy & 1992 & Cattle/lung & E1 \\
\hline 6472 & LPB & Italy & 1992 & Cattle/lung & $\mathrm{E} 1$ \\
\hline 6473 & LPB & Italy & 1992 & Cattle/lung & E1 \\
\hline 6476 & LPB & Italy & 1992 & Cattle/lung & E1 \\
\hline 6478 & LPB & Italy & 1992 & Cattle/lung & $\mathrm{E} 1$ \\
\hline 6479 & LPB & Italy & 1992 & Cattle/lung & $\mathrm{E} 2$ \\
\hline 6424 & LPB & Italy & 1992 & Buffalo & E1 \\
\hline 6514 & LPB & Italy & 1992 & Cattle/lung & E1 \\
\hline 6865 & LPB & Italy & 1993 & Cattle/lung & E1 \\
\hline 6866 & LPB & Italy & 1993 & Cattle/lung & E1 \\
\hline 6970 & LPB & Italy & 1992 & Cattle/lung & E1 \\
\hline 6981 & LPB & Italy & 1992 & Cattle/lung & E1 \\
\hline Afadé & CIRAD & Chad & 1968 & Cattle & A1 \\
\hline Fatick & CIRAD & Senegal & 1968 & Cattle & $\mathrm{A} 1$ \\
\hline B17 & CIRAD & Chad & 1967 & Zebut & $\mathrm{A} 1$ \\
\hline Gemu Gofa & CIRAD & Ethiopia & 1974 & Cattle & A1 \\
\hline 7721 & CIRAD & Mauritania & 1977 & Cattle & A1 \\
\hline Filfili & CIRAD & Senegal & pre-1988 & Cattle & A3 \\
\hline Dakar 2144 & CIRAD & Senegal & pre-1968 & Cattle & A1 \\
\hline 2162 & CIRAD & Senegal & pre-1968 & Cattle & A1 \\
\hline $9050-529 / 1$ & CIRAD & $\begin{array}{l}\text { Ivory } \\
\text { Coast }\end{array}$ & 1990 & Cattle & A5 \\
\hline $87137-9$ & CIRAD & $\begin{array}{c}\text { Burkina } \\
\text { Faso }\end{array}$ & 1987 & Cattle & A5 \\
\hline Asmara & CIRAD & Eritrea & 1970 & Cattle & A1 \\
\hline
\end{tabular}


Table 1. (cont.)

\begin{tabular}{|lllcll|}
\hline Strain & Collection* & Origin & Isolated & Host & $\begin{array}{c}\text { IS1296 } \\
\text { pattern }\end{array}$ \\
\hline 91130 & & & & & A1 \\
& CIRAD & C. African & 1991 & Cattle & \\
93151 & Rep. & & & A1 \\
C 11 & CIRAD & Namibia & 1993 & Cattle & A1 \\
94111 & CIRAD & Chad & 1962 & Cattle & A6 \\
95014 & CIRAD & Rwanda & 1994 & Cattle & A1 \\
T1/44 & CIRAD & Tanzania & 1995 & Cattle & A4 \\
T1Sr & CIRAD & Tanzania & 1952 & Cattle/vaccine strain $\ddagger$ & A4 \\
T1Sr/50 & CIRAD & Tanzania & 1952 & Cattle/vaccine strain & A4 \\
KH3J & CIRAD & Tanzania & 1952 & Cattle/vaccine strain\| & A2 \\
Gladysdale & CIRAD & Sudan & 1940 & Cattle/vaccine straing & A1 \\
DVZ & AAHL & Australia & & Cattle & A1 \\
R575 & AAHL & Australia & 1965 & Cattle & A1 \\
CF1 & AAHL & Australia & $1965-8$ & Cattle & A1 \\
V5 & AAHL & Australia & $1965-8$ & Cattle & A7 \\
\hline
\end{tabular}

* AAHL, Australian Animal Health Laboratory, Geelong, Victoria, Australia; CIRAD, CIRAD-EMVT, Maisons-Alfort, France; IVBBE, Institute for Veterinary Bacteriology, Berne, Switzerland; LPB, Laboratoire de Pathologie Bovine, Lyon, France; LNV, Laboratorio Nacional de Veterinaria, Lisboa, Portugal; NCTC, National Collection of Type Cultures, PHLS, London, UK.

† Complement fixation test antigen.

$\ddagger$ Vaccine strain (Piercy \& Knight, 1956), passage 44.

$\S$ Streptomycin-resistant vaccine strain, derived from strain T1 (Provost, 1969).

|| Streptomycin-resistant vaccine strain (Provost, 1969), passage 50, FAO-approved master seed bank; identical to strain T1Sr.

I Ancestral vaccine strain (Provost, 1969).

gave the best resolution on standard gels, we used this enzyme for further analysis as a standard method for fingerprinting.

\section{Analysis of IS1296 patterns}

We analysed 63 strains of $M$. mycoides subsp. mycoides SC from different countries and continents and the type strain PG1 [directly from the National Collection of Type Cultures (NCTC), Public Health Laboratory Service, London, UK, or subcultured by another laboratory] by IS1296 fingerprinting. The strains were collected between 1940 and 1995 (Africa), between 1965 and 1968 (Australia) and between 1980 and 1993 (Europe) (unfortunately no European strains from the period before 1960 were available). Among these strains, we distinguished ten different IS1296 patterns (Fig. 1) named E1, E2, A1-A7 and $\mathrm{P}$ (Table 1). The relationships among the IS patterns are presented as an evolutionary network connecting the observed genotypes in Fig. 2. In this diagram where the different patterns are interlinked by differences of one IS band, two main clusters can be observed. One cluster included all 39 strains isolated in Europe, which showed two different patterns, while the second cluster, which showed six different patterns, contained the strains isolated from Africa and Australia and the type strain PG1. The first cluster contained 38 strains with pattern E1 and only one strain with pattern E2, which was derived from E1 (Fig. 2). In the second cluster, the majority of strains (16) belong to pattern A1, the other eight strains which include the type strain PG1 share five different patterns, each of them being related to A1 by one different IS band (Fig. 2). Two strains, one of them being an ancestral African vaccine strain formed separate patterns (A2 and A6) belonging to neither of the two main clusters.

\section{Epidemiologic investigations}

Among the 39 European strains from France, Italy, Portugal and Spain, all except one had the same pattern (E1). The single strain that differed showed pattern E2 which differed from E1 by having one additional IS1296 copy, hence belonging to the same cluster (Table 1 and Fig. 2). The hybridization patterns of a few selected strains are shown in Fig. 1. One strain isolated from a buffalo in Italy showed pattern E1 like the majority of European bovine strains. Portuguese bovine strains isolated from bovine semen or preputial washings (Goncalves, 1994) also showed the IS1296 pattern E1, like most bovine strains which are generally isolated from lungs affected by CBPP. Of particular interest are several strains isolated from species other than cattle. Two $M$. mycoides subsp. mycoides SC strains isolated from caprine pneumonic lungs and three SC strains isolated from the milk of sheep with mastitis (Brandao, 1995) also showed 

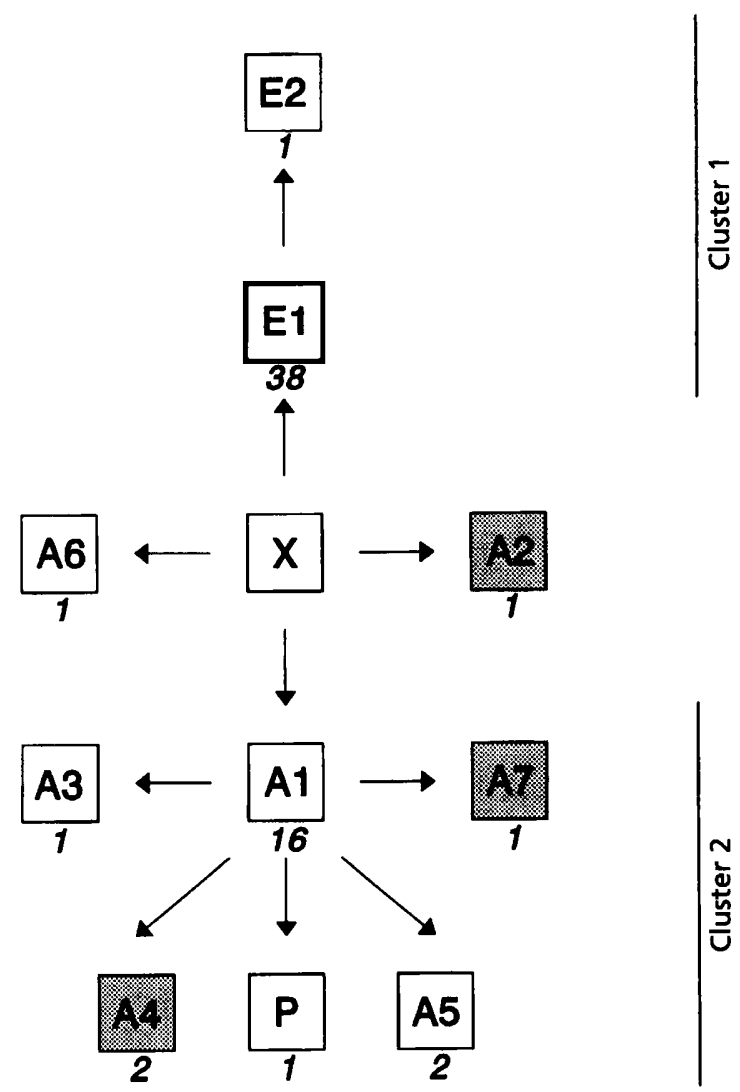

Fig. 2. Evolutionary network of the different genotypes as discovered by IS1296 fingerprinting. The boxes represent the different IS1296 patterns with the number of strains indicated below the box. Pattern $X$ is a hypothetical pattern with 17 bands which are common to all the patterns actually observed. The arrows show the directions towards a pattern $(X)$ with an additional band, assuming that all patterns observed arose from an ancestral pattern by adding copies of IS1296 via transposition. The shaded boxes represent patterns of vaccine strains. The individual strains belonging to each of these patterns are given in Table 1.

pattern E1 which confirms their belonging to the same clonal line as strains isolated from cattle and buffalo.

The 24 strains originating from Africa and Australia showed seven different IS1296 patterns, A1-A7 (Table 1 and Fig. 1). Most field isolates from Africa and Australia showed the same pattern, A1, with only four exceptions. One strain isolated from Senegal had IS pattern A3, and each strain from both the Ivory Coast and from Burkina Faso had pattern A5. Both patterns A3 and A5 are closely related to $\mathrm{A} 1$, belonging to the same cluster. One field strain, isolated in Rwanda showed an IS pattern which was more distant from A1. All vaccine strains showed individual IS1296 patterns. The attenuated strain T1 originally isolated in Tanzania and its streptomycinresistant derivative, $\mathrm{T} 1 \mathrm{Sr}$, which is currently the officially Food and Agriculture Organization (FAO)-approved vaccine strain, showed an identical pattern $A 4$ belonging to cluster 2, grouping the African and Australian strains (Figs 1 and 2). This confirms the common origin of T1 and $\mathrm{T} 1 \mathrm{Sr}$ and indicates that the streptomycin resistance in
T1Sr is not IS1296-induced. Different passages of T1 and T1Sr also showed the same pattern, A4 (Table 1). The vaccine strain V5 from Australia also showed an individual pattern, A7, belonging to cluster 2, while the ancestral vaccine strain, $\mathrm{KH} 3 \mathrm{~J}$, originating from Sudan showed pattern A2 which, like pattern A6, forms an outgroup (Table 1 and Figs 1 and 2).

The type strain PG1 had an individual pattern belonging to the second cluster (Fig. 2). It was most closely related to pattern A1 of the African and Australian field strains (Fig. 2). Cultures of PG1 from two different sources, one from the NCTC and a second from the Laboratory of Bovine Pathology (LPB; Lyon, France) revealed the same pattern, thus indicating that IS1296 transposes infrequently in M. mycoides subsp. mycoides SC.

\section{DISCUSSION}

Identification of individual strains or lineages of strains of M. mycoides subsp. mycoides SC has not been possible to date due to a lack of appropriate markers and methods. Since Mycoplasma species, like Mycobacterium tuberculosis, have a low number of $r r n$ genes, ribotyping, which is generally the method of choice for genetic subtyping of strains, is not applicable. IS fingerprinting, however, has proved to be particularly useful where ribotyping did not result in sufficient discrimination between strains (van Embden et al., 1993; Small et al., 1994; Stanley et al., 1993). With a view to short-term evolutionary analysis of $M$. mycoides subsp. mycoides SC strains which are currently available from various countries and continents, and for epidemiological investigations, we have developed a method of DNA typing of $M$. mycoides subsp. mycoides SC strains which is based on polymorphisms generated by variabilities in the copy number and chromosomal position of IS1296. Our investigations of 64 strains from various countries and continents including four vaccine strains and the type strain PG1 revealed two main clusters which must have separated some time ago and which are confined to different continents. One cluster contains strains from Europe and the second cluster contains strains from Africa and Australia. The type strain PG1, whose origin is unknown, belongs to the cluster of strains from Africa and Australia.

From the analysis of the field strains it is interesting to note that nearly all European strains had IS1296 pattern $\mathrm{E} 1$ and the majority of the African and Australian strains had pattern A1, each belonging to a different cluster (Fig. 2). This clonal stability of IS1296 patterns is mostly documented by the European field strains which originate from four different countries and were isolated during outbreaks within the last 15 years. One exception, strain 6479 from Italy, showed a different pattern with an additional copy of IS1296. Further, more detailed local epidemiological studies using IS1296 fingerprinting will reveal whether this clonal lineage is emerging in certain areas or whether this IS1296 pattern (E2) is a rare event. The results, however, show that IS1296 transposes infrequently and that the patterns are highly stable in field strains. 
Among the African field strains the heterogeneity of IS1296 patterns is larger. This might be due to the fact that the disease has been endemic in Africa for a long time and is also spread more than during the outbreaks in Europe. IS1296 fingerprinting therefore seems applicable for epidemiological studies in Africa. In this view, it is interesting to note that the only strains used in this study from the Ivory Coast and from Burkina Faso, countries which are known to have frequent exchanges of cattle, showed a common particular IS pattern (A5) which is different from all other strains. All of the Australian field strains analysed showed the same IS pattern (A1) as did most of the African field strains. They must therefore be of common origin. It has to be remembered that it was assumed that CBPP was introduced into Australia in 1858 by infected cattle from England (ter Laak, 1992). This may lead to the speculation that a strain related to the strains found in Africa (cluster 2) was present in the European epizootical situation of the 19th century, or that the introduction of CBPP to Australia was of different origin. At the moment, the few strains investigated in this study, however, do not allow the establishment of a more precise epidemiological relationship of CBPP at an international level.

All vaccine strains analysed in this study showed particular IS1296 patterns. Strains T1 and T1Sr (Africa) and V5 (Australia) had IS patterns belonging to cluster 2, confirming their descendence from African/Australian isolates. Strain KH3J, which is an ancestral vaccine strain, had an IS pattern outside of the main clusters (Fig. 2). However, more strains from the African continent have to be investigated to confirm the singularity of the patterns of the vaccine strains and to validate the method for identification of vaccine strains.

It is interesting to note that the type strain of $M$. mycoides subsp. mycoides SC, PG1, whose origin is not known and which has apparently become non-pathogenic (Edward \& Freundt, 1973), is closely related to the African and Australian field strains. Only one difference is observed between pattern P of PG1 and pattern A1 of the African and Australian field strains. It can therefore be assumed that PG1 originates from a strain belonging to the lineage of pattern $\mathrm{A} 1$ which might during multiple passages have undergone an IS1296 transposition event before having been deposited as the type strain. This may also account for the loss of its pathogenicity.

Despite the fact that $M$. mycoides subsp. mycoides SC is generally described as specific to large ruminants, isolation of $M$. mycoides subsp. mycoides $\mathrm{SC}$ from small ruminants has been reported (Goncalves et al., 1994). We have therefore analysed two strains isolated from caprine lungs (C305 and $\mathrm{C} 425$ ) and three strains isolated from ovine milk (O326, O512, O526). IS1296 fingerprints clearly show that these strains belong to the same clonal lineage as the strains isolated from CBPP outbreaks in Europe. Small ruminants therefore represent potential reservoirs for $M$. mycoides subsp. mycoides SC and must therefore be included in investigations and programmes for the control of
CBPP. A further interesting aspect is the uncommon localization of $M$. mycoides subsp. mycoides SC with the same IS1296 pattern as CBPP strains from semen or preputium of bulls. This fact should also be taken into account in the elucidation of the chain of infection.

Fingerprinting of $M$. mycoides subsp. mycoides SC strains with IS1296 is an efficient method giving highly reproducible results which can be used for epidemiological subtyping and for the identification of strains, especially vaccine strains. Moreover it has allowed us to identify two clonal lines, one representing strains from the European continent and a second including African and Australian strains.

\section{ACKNOWLEDGEMENTS}

We are grateful to Margrit Krawinkler for expert help with preparations of Mycoplasma cultures. We thank F. DeSimone, Istituto Zooprofilattico Sperimentale della Lombardia e dell'Emilia, Brescia, Italy; P. C. Lefevre, CIRAD-EMVT, Maisons-Alfort, France; F. G. Santini, Istituto Zooprofilattico Sperimentale dell'Abruzzo e del Molise, Teramo, Italy; and T. Taylor, Australian Animal Health Laboratory, Geelong, Victoria, Australia, for gift of strains. We thank A. Burnens, National Center for Foodborne Diseases, Berne, Switzerland and J. Stanley, PHLS, London, UK, for valuable comments and editorial help. This study is part of the European COST action 826 on ruminants' mycoplasmoses and was supported by a grant from the Federal Swiss Veterinary Office.

\section{REFERENCES}

Abu Groun, E. A. M., Taylor, R. R., Varsani, H., Wadher, B. J., Leach, R. H. \& Miles, R. J. (1994). Biochemical diversity within the 'Mycoplasma mycoides' cluster. Microbiology 140, 2033-2042.

Ausubel, F. M., Brent, R., Kingston, R. E., Moore, D. D., Seidman, J. G., Smith, J. A. \& Struhl, K. (1990). Current Protocols in Molecular Biology, vol. 1. New York: Wiley Interscience.

Bannerman, E. S. \& Nicolet, J. (1971). Isolation and identification of porcine Mycoplasma in Switzerland. Schweiz Arch Tierheilled 113, 697-710.

Bashiruddin, J. B., Nicholas, R. A. J., Santini, F. G., Ready, R. A., Woodward, M. J. \& Taylor, T. K. (1994a). Use of the polymerase chain reaction to detect mycoplasma DNA in cattle with contagious bovine pleuropneumonia. Vet Rec 134, 240-241.

Bashiruddin, J. B., Taylor, T. K. \& Gould, A. R. (1994b). A PCRbased test for the specific identification of Mycoplasma mycoides subspecies mycoides SC. J Vet Diagn Invest 6, 428-434.

Brandao, F. (1995). Isolation and identification of Mycoplasma mycoides subspecies mycoides SC strains in sheep and goats. Vet Rec 136, 98-99.

Brocchi, E., Gamba, D., Poumarat, F., Martel, J. L. \& De Simone, F. (1993). Improvements in the diagnosis of contagious bovine pleuropneumonia through the use of monoclonal antibodies. Rev Sci Tech Off Int Epiz 12, 559-570.

Costas, M., Leach, R. H. \& Mitchelmore, D. L. (1987). Numerical analysis of PAGE protein patterns and the taxonomic relationships within the 'Mycoplasma mycoides cluster'. J Gen Microbiol 133, 3319-3329. 
Cottew, G. S., Breard, A., DaMassa, A. J., Ernø, H., Leach, R. H. Lefevre, P. C., Rodwell, A. W. \& Smith, G. R. (1987). Taxonomy of the Mycoplasma mycoides cluster. Isr J Med Sci 23, 632-635.

Dedieu, L., Mady, V. \& Lefevre, P. C. (1994). Development of a selective polymerase chain reaction assay for the detection of Mycoplasma mycoides subsp. mycoides SC (contagious bovine pleuropneumonia agent). Vet Microbiol 42, 327-339.

Edward, D. G. \& Freundt, E. A. (1973). Type strains of species of the order Mycoplasmatales, including designation of neotypes for Mycoplasma mycoides subsp. mycoides, Mycoplasma agalactiae subsp. agalactiae, and Mycoplasma artbritidis. Int J Syst Bacteriol 23, 55-61.

van Embden, J. D., Cave, M. D., Crawford, J. T., Dale, J. W., Eisenach, K. D., Gicquel, B., Hermans, P., Martin, C., McAdam, R. \& Shinnick, T. M. (1993). Strain identification of Mycobacterium tuberculosis by DNA fingerprinting: recommendations for a standardized methodology (see comments). J Clin Microbiol 31, 406-409.

Frey, J., Cheng, X., Kuhnert, P. \& Nicolet, J. (1995). Identification and characterization of IS1296 in Mycoplasma mycoides subsp. mycoides SC and presence in related mycoplasmas. Gene 160, 95-100.

Galas, D. J. \& Chandler, M. (1989). Bacterial insertion sequences. In Mobile DN $A$, pp. 109-162. Edited by D. E. Berg \& M. M. Howe. Washington, DC: American Society for Microbiology.

Goncalves, M. R. (1994). Isolation and identification of Mycoplasma mycoides subspecies mycoides $\mathrm{SC}$ from bull semen and sheath washings in Portugal. Vet Rec 135, 308-309.

Goncalves, R., Regalla, J. \& Penha-Goncalves, A. (1994). Immunoblotting and electrophoretic analysis of Mycoplasma mycoides subsp. mycoides SC strains isolated from bovine and small ruminants. Int Organ Mycoplasmol Lett 3, 64.

ter Laak, E. A. (1992). Contagious bovine pleuropneumonia. A review. Vet $Q 14,104-110$.
Nocard, E. I. E. \& Roux, E. (1898). Le microbe de la péripneumonie. Ann Inst Pasteur 12, 240-262. [Translated as 'The microbe of pleuropneumonia' in Rev Infect Dis 12, 354-358 (1990)]

Piercy, S. E. \& Knight, G. J. (1956). Studies with avianised strains of the organism of contagious bovine pleuro-pneumonia. Vet $\operatorname{Rec} 68$, 367-373.

Poumarat, F. \& Solsona, M. (1994). Molecular epidemiology of Mycoplasma mycoides subsp. mycoides biotype 'small colony' (M.m.m. SC). Int Organ Mycoplasmol Lett 3, 23.

Provost, A. (1969). Principes de production d'un vaccin mixte associe antibovipestique-antiperipneumonique inocule en un seul temps. Bull Epizoot Dis Afr 17, 7-10.

Pyle, L. E., Taylor, T. \& Finch, L. R. (1990). Genomic maps of some strains within the Mycoplasma mycoides cluster. J Bacteriol 172, 7265-7268.

Small, P. M., Hopewell, P. C., Singh, S. P., Paz, A., Parsonnet, J., Ruston, D. C., Schecter, G. F., Daley, C. L. \& Schoolnik, G. K. (1994). The epidemiology of tuberculosis in San Francisco. A population-based study using conventional and molecular methods $N$ Engl J Med 330, 1703-1709.

Stanley, J., Baquar, N. \& Threlfall, E. J. (1993). Genotypes and phylogenetic relationships of Salmonella typhimurium are defined by molecular fingerprinting of IS200 and $16 \mathrm{~S} \mathrm{rrn} \mathrm{loci.} \mathrm{J} \mathrm{Gen} \mathrm{Microbiol}$ 139, 1133-1140.

Taylor, T. K., Bashiruddin, J. B. \& Gould, A. R. (1992). Relationships between members of the Mycoplasma mycoides cluster as shown by DNA probes and sequence analysis. Int J Syst Bacteriol 42, 593-601.

Received 28 July 1995; accepted 16 August 1995 